\section{ALAPE 2012}

Sr. Editor:

En nombre del Comité Organizador, nos gustaría informarle que el XVI Congreso Latinoamericano de Pediatría ALAPE 2012, que tendrá lugar en Cartagena de Indias, Colombia del 14 al 18 de noviembre de 2012.

El Congreso, nuestra principal reunión académica regional, de acuerdo a los nuevos estatutos es organizado por ALAPE, teniendo, en esta ocasión, como anfitriona y colaboradora a la Sociedad Colombiana de Pediatría. Está dirigido a principalmente a pediatras y trabajadores de la salud infantil, como también a enfermeras, terapeutas, nutricionistas, psicólogos y médicos de familia.

Los principales ejes temáticos son: neona- tología, enfermedades infecciosa/vacunas, nutrición, medicina del adolescente y del deporte, con énfasis en atención primaria, teniendo en cuenta al niño, niña y adolescentes como sujeto de derechos.

En forma transversal se integran adicionalmente, entre otros temas, neumología, cuidado en casa, prevención de accidentes, salud mental, violencia y maltrato, abogacía, y el niño, los medios e internet, una de las áreas de experticia de nuestra Asociación.

Para mayor información sobre el Congreso de ALAPE 2012, le invitamos a visitar la página web del congreso: http://www.congresosalape.com

Sarah Krein ALAPE 2012 Congress, Marketing and Sales Manager Paragon Conventions. 